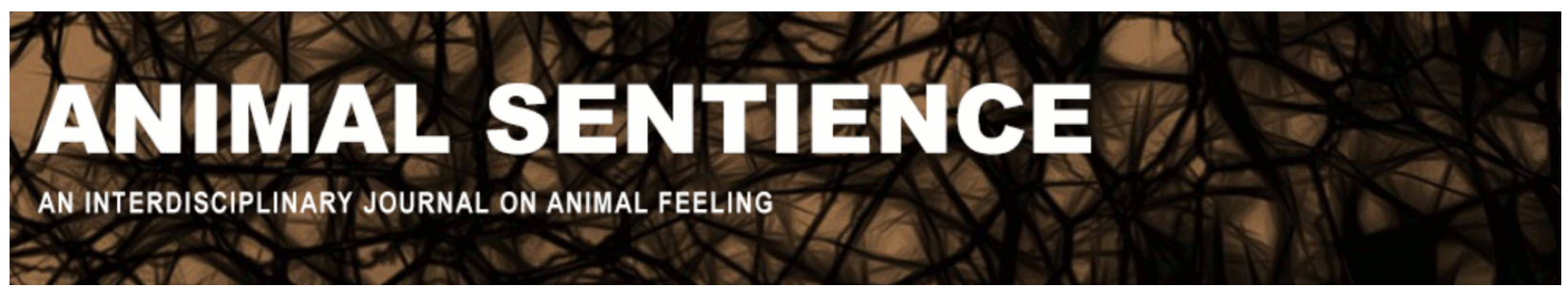

Sneddon, Lynne U. and Leach, Matthew C. (2016) Anthropomorphic denial of fish pain. Animal Sentience 3(28)

DOI: $10.51291 / 2377-7478.1048$

Date of submission: $2015-10-23$

Date of acceptance: 2015-12-13

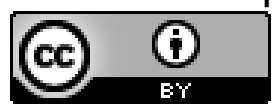

This article has appeared in the journal Animal

Sentience, a peer-reviewed journal on animal

cognition and feeling. It has been made open access,

free for all, by WellBeing International and deposited

in the WBI Studies Repository. For more information,

please contact

wbisr-info@wellbeingintl.org.

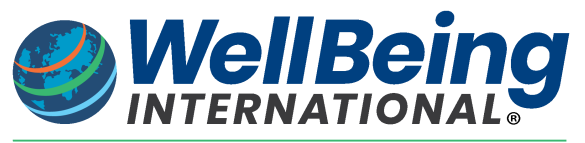

SOLUTIONS FOR PEOPLE, ANIMALS AND ENVIRONMENT 


\title{
Anthropomorphic denial of fish pain
}

\author{
Commentary on Key on Fish Pain
}

\author{
Lynne U. Sneddon \\ University of Liverpool \\ Matthew C. Leach
}

Newcastle University

\begin{abstract}
Key (2016) affirms that we do not know how the fish brain processes pain but denies - because fish lack a human-like cortex - that fish can feel pain. He affirms that birds, like fish, have a singly-laminated cortex and that the structure of the bird brain is quite different from that of the human brain, yet he does not deny that birds can feel pain. In this commentary we describe how Key cites studies that substantiate mammalian pain but discounts the same kind of data as evidence of fish pain. We suggest that Key's interpretations are illogical, do not reflect the published empirical evidence for pain in fish, and are out of touch with current thinking on brain evolution. We agree that more scientific data are needed to understand how the brains of fish - and other organisms - function. But the incompleteness of current knowledge certainly does not constitute evidence for inferring that fish in particular do not feel pain.
\end{abstract}

Lynne U. Sneddon Isneddon@liverpool.ac.uk is Director of Bioveterinary Science at the University of Liverpool. She was one of the first scientists to discover nociceptors that detect painful stimuli in fish. Sneddon has since published empirical studies that drive the fish welfare agenda in many contexts.

http://www.liv.ac.uk/integrative-biology/staff/lynne-sneddon/

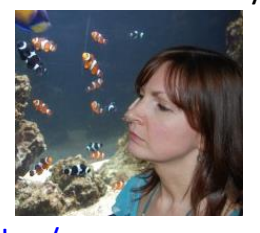

Matthew Leach matthew.leach@ncl.ac.uk is a member of the Pain \& Animal
Welfare Science Group at Newcastle University, which is
internationally recognised for work on assessing and
alleviating mammalian pain. Leach's current work aims to
gauge pain noninvasively through the use of grimace scales.
http://www.ncl.ac.uk/cbe/people/profile/matthew.leach

No animal can directly communicate its experience to us; hence, we cannot know for sure whether or what it does or does not feel. Key (2016) argues that fish in particular do not experience or "feel" pain - he apologises for the use of the term "feel" - because they lack a human cortex. Without such a cortex, an organism cannot have phenomenal consciousness: the internal subjective experience or feeling associated with an event or stimulus - in the case of painful stimuli, the experience of discomfort or suffering.

Key's position is not new. Sceptics such as Rose (2002) and Rose, Arlinghaus, Cooke, Diggles, Sawynok, Stevens, and Wynne (2015) have been making the same argument. Key cites these authors, but fails to point out that they have not published any empirical studies of their own to show that fish do not feel pain; they have only published selective reviews, ignoring papers that do not support their position. Rose et al. have been criticised for not stating that on their account birds, too, could not possibly experience pain - in fact, no animal other than primates could - because birds, like fish, have only a singly laminated cortex. Rose (2016) further states in his commentary on Key (this journal) that fish do not have many $C$ fibres that convey multi-modal noxious information in mammals yet he fails to 
acknowledge that fish A-delta fibres actually perform the same role (reviews in Sneddon 2015; Sneddon et al. 2014). Rose also proposes that the behavioural responses of fish are simply reflexes -- yet these prolonged behavioural responses to painful stimulation in fish can be seen for at least hours and even days later. Furthermore, providing analgesia substantially reduces these adverse changes in behaviour in fish: this same evidence would be accepted as evidence of pain in mammals (Sneddon 2015; Sneddon et al. 2014).

Those who propose that fish cannot feel pain have also been criticized for not taking into account species differences in environment and evolutionary history that can result in differences in brain development, including differences in the mechanisms of pain processing (Sneddon 2015; Sneddon et al. 2014). Key's target article, like its antecedents, is vulnerable to these objections. Key argues that it is anthropomorphic to suggest that fish feel pain: one should not extrapolate from the human condition to an animal. Yet Key then takes the equally anthropomorphic view that because fish lack the organisation and operation of the human brain (specifically the layered cortex), they cannot feel pain. His supporting examples also appear to be inconsistent: Morphine works in rats by acting centrally, so Key accepts that rats feel pain, but then he goes on to argue that one cannot use that as evidence for pain in fish because we do not know how morphine works in fish. This is to ignore the molecular evidence that opioid receptors are highly conserved in fish (Dores et al. 2002) and that in fish morphine acts in much the same way as effective painkillers in other species do: it reduces adverse changes in complex behavioural responses after a painful event (Sneddon 2003; Sneddon et al. 2003). Other painkilling drugs likewise have much the same effect in fish (Mettam et al. 2011).

Studies have shown a stress response in fish to stimuli that would in other species be expected to cause pain (Sneddon 2015). Key appears to suggest that although pain is inherently stressful, the stress response shown to be elicited in mammals is indicative of pain in mammals, but not in fish. Key also argues that although we do not fully understand how birds process pain, he is willing to accept that pain can occur in birds; however, because we do not know enough about how fish process pain, they cannot experience pain.

We can certainly agree that we do not yet know enough about how pain is processed in the brains of many species. For fish we know there is electrophysiological activity during painful stimulation and that there exist differences in gene expression at the molecular level for the effects of noxious versus innocuous stimuli. Functional magnetic resonance imaging likewise reveals a profound change in forebrain activity in fish during painful stimulation (Reilly et al. 2008; Dunlop \& Laming 2005; Nordgreen et al. 2007; Sneddon 2011). Key states that this brain activity is not symptomatic of pain even though the same data would be accepted as such in rodent species that are routinely used as clinical models for human pain (Sneddon et al. 2014). If such evidence is acceptable for mammalian pain, it is not at all clear why Key discounts it as evidence of fish pain.

This kind of selective and somewhat circular reasoning, verging on special pleading, is used repeatedly throughout Key's target article: Rats can learn to avoid noxious stimuli, which is taken as evidence of their feeling pain; fish too can learn to avoid such noxious stimuli, but in their case this is not evidence of feeling pain. Key also asserts, incorrectly, that fish not show the reduction in activity after injury that is interpreted in mammals as a protective response to pain to promote healing: This same response has in fact been demonstrated in a number of fish species (Sneddon 2015).

Fish are capable of very complicated behaviours, including deception, problem solving, forming relationships within and between species, and using gestures and sounds to communicate. Studies by Bshary and Brown (2014) and Bshary, Gingins, and Vail (2014) are challenging old dogma regarding the size and complexity of brains. According to the social brain theory, primates have larger brains for their body size because of their complicated social and cognitive skills. Yet Bshary's research has shown that fish too are capable of many complex, skilled and intricate behaviours that require higher cognitive processes. Indeed, fish are quicker to solve some problems than capuchin 
monkeys, and they can manipulate other organisms even with their relatively small brains (Abbott 2015). A recent study in rabbitfishes has shown that they are capable of direct reciprocity in foraging and vigilance behaviour elegantly matching a partner's behaviour. This complicated capacity requires higher cognitive and social skills seen only in a few mammals and birds (Brandl \& Bellwood 2015).

The anthropomorphism in the target article is misguided and illogical. Key fails to cite published studies that provide opposing evidence and adds nothing new to the debate on pain perception in fish. More scientific data are needed to understand how the brains of fish (and other organisms) function. But the incompleteness of current knowledge certainly does not constitute evidence for inferring that fish in particular do not feel pain. Key's target article is out of touch with current thinking and evidence on brain evolution, and it fails to take into account much of the available evidence on consciousness in fish (Sneddon 2011; Brown 2015). Sceptics about fish pain might have made some progress, however: Now that they accept that birds can feel pain, perhaps one day they may change their minds on fish.

\section{References}

Abbott, A. (2015). Animal behaviour: Inside the cunning, caring and greedy minds of fish. Nature 521, 412-414.

Brandl, S. J. \& Bellwood, D. R. (2015). Coordinated vigilance provides evidence for direct reciprocity in coral reef fishes. Sci. Rep. 5, 14556. doi: 10.1038/srep14556.

Brown, C. (2015). Fish intelligence, sentience and ethics. Anim. Cog. 18, 1-17.

Bshary, R. \& Brown, C. (2014). Fish cognition. Curr. Biol., 24(19), R947-R950.

Bshary, R., Gingins, S. \& Vail, A. L. (2014). Social cognition in fishes. Trends Cogn. Sci., 18(9), 465-471.

Dores, R. M., Lecaude, S., Bauer, D. \& Danielson, P. B. (2002). Analyzing the evolution of the opioid/orphanin gene family. Mass Spectrom. Rev. 21, 220-243.

Dunlop, R. \& Laming, P. (2005). Mechanoreceptive and nociceptive responses in the central nervous system of goldfish (Carassius auratus) and trout (Oncorhynchus mykiss). J. Pain 6, 561-568.

Key, B. (2015). Fish do not feel pain and its implications for understanding phenomenal consciousness. Biol. Phil. 30, 149-165.

Key, B. (2016). Why fish do not feel pain. Animal Sentience 2016.003.

Mettam, J.M., Oulton, L.J., McCrohan, C.R. \& Sneddon, L.U. (2011). The efficacy of three types of analgesic drug in reducing pain in the rainbow trout, Oncorhynchus mykiss. Appl. Anim. Behav. Sci. 133, 265-274.

Nordgreen, J., Horsberg, T.E., Ranheim, B. \& Chen, A.C.N. (2007). Somatosensory evoked potentials in the telencephalon of Atlantic salmon (Salmo salar) following galvanic stimulation of the tail. J. Comp. Physiol. Part A 193, 1235-1242.

Reilly, S.C., Quinn, J.P., Cossins, A.R. \& Sneddon, L.U. (2008). Novel candidate genes identified in the brain during nociception in common carp (Cyprinus carpio) and rainbow trout (Oncorhynchus mykiss). Neurosci. Lett. 437, 135-138.

Rose, J.D. (2002). The neurobehavioral nature of fishes and the question of awareness and pain. Rev. Fish. Sci. 10, 1-38.

Rose, J.D., Arlinghaus, R., Cooke, S.J., Diggles, B.K., Sawynok, W., Stevens, E.D. \& Wynne, C.D.L. (2015). Can fish really feel pain? Fish Fish. 15, 97-133.

Rose, J.D. (2016). Weighing the evidence. Animal Sentience 2016.032.

Sneddon L.U. (2003). The evidence for pain in fish: the use of morphine as an analgesic. Appl. Anim. Behav. Sci. 83, 153-162.

Sneddon, L.U. (2011). Pain perception in fish: Evidence and implications for the use of fish. J. Conscious. Stud. 18, 209-229 Sneddon, L.U. (2015). Pain in aquatic animals. J. Exp. Biol. 218, 967-976.

Sneddon, L.U., Braithwaite, V.A. \& Gentle, M.J. (2003). Novel object test: examining nociception and fear in the rainbow trout. J. Pain 4, 431-440.

Sneddon, L.U., Elwood, R.W. Adamo S. \& Leach, M.C. (2014). Defining and assessing pain in animals. Anim. Behav. 97, $201-212$. 